\title{
Sistem Informasi Geografis Monitoring Dan Evaluasi Proyek Dinas Pekerjaan Umum Kota Kotamobagu
}

\author{
Dadang H. Makalalag, Yaulie Deo Y. Rindengan, Rizal Sengkey \\ Teknik Informatika Universitas Sam Ratulangi. Manado, Indonesia \\ 110216091@student.unsrat.ac.id, rindengan@gmail.com, rizalsengkey@gmail.com
}

\begin{abstract}
Abstrak - Monitoring dan Evaluasi Proyek merupakan salah satu pekerjaan yang sering dilakukan oleh Dinas Pekerjaan Umum Kota Kotamobagu untuk memaksimalkan pembangunan daerah. Dinas Pekerjaan Umum (PU) sendiri memiliki kesulitan dalam memonitoring dan mengevalusai proyek yang sedang berjalan maupun proyek yang sudah direalisasikan, Selama ini proyek-proyek diawasi satu persatu secara manual dikarenakan Dinas Pekerjaan Umum (PU) belum memiliki sistem informasi yang bisa mengawasi dan mengevaluasi semua proyek secara bersamaan dan juga memberikan gambaran geografis lokasi proyek secara keseluruhan. Menggunakan metodologi pengembangan Sistem Perangkat Lunak Rapid Application Development (RAD) peneliti membuat Rancang Bangun Aplikasi Website ini untuk memecahkan masalah tersebut. Sistem Dibangun Menggunakan Bahasa Pemograman PHP serta Google Maps API. Hasil dari penelitian ini adalah sebuah aplikasi Website Sistem Informasi Geografis (SIG) Monitoring dan Evaluasi Proyek Dinas Pekerjaan Umum Kota Kotamobagu.
\end{abstract}

Kata kunci: Evaluasi, Monitoring, Proyek, RAD, SIG.

\section{PENDAHULUAN}

Perkembangan teknologi sangat berpengaruh terhadap kehidupan manusia, dengan berbagai kemudahan yang ditawarkan semua pekerjaan, kegiatan dan informasi bisa lebih mudah di akses, Sistem informasi merupakan salah satu teknologi tersebut. Sistem Informasi adalah suatu sistem buatan manusia yang secara umum terdiri atas sekumpulan komponen berbasis komputer dan manual yang dibuat untuk menghimpun, menyimpan dan mengelola data serta menyediakan informasi keluaran kepada pemakai (Gelinas, Oram dan Wiggins : 1990). Sistem informasi adalah kumpulan perangkat keras dan perangkat lunak yang dirancang untuk mentransformasikan data kedalam bentuk informasi yang berguna (Bodnar dan Hopwood : 1993).

Sistem Informasi Geografis (SIG) atau juga dikenal sebagai Geographic Information Sistem (GIS) akhir - akhir ini mengalami perkembangan yang berarti seiring kemajuan teknologi informasi. SIG merupakan sistem informasi berbasis komputer yang menggabungkan antara unsur peta (geografis) dan informasinya tentang peta tersebut (data atribut) yang dirancang untuk mendapatkan, mengelolah, memanipulasi, analisa, memperagakan dan menampilkan data spasial untuk menyelesaikan perencanaan, mengolah dan meneliti permasalahan (Jati Bangun : 2011). Penggunaan data geografis ini dapat digunakan untuk mengatasi masalah disegala bidang, dalam bidang pemerintahan SIG dapat digunakan untuk memonitoring dan mengevaluasi proyek dari Dinas Pekerjaan Umum.

Dinas Pekerjaan Umum Daerah Kota Kotamobagu merupakan salah satu satuan kerja perangkat daerah (SKPD) dengan visinya: "Tersedianya infrastuktur Pekerjaan Umum yang handal dan bermanfaat secara berkelanjutan serta berbasis tataruang untuk mendorong terwujudnya Kota Kotamobagu sebagai pusat pertumbuhan ekonomi regional menuju masyarakat sejahtera, sehat, cerdas dan berbudaya". Dinas yang berkerja untuk berbagai pembangunan daerah seperti Proyek Jembatan, Jalan, dan lain-lain ini, memiliki kesulitan dalam memonitoring dan mengevalusai proyek yang sedang berjalan maupun proyek yang sudah direalisasikan. Selama ini proyek-proyek diawasi satu persatu secara manual, dikarenakan Dinas Pekerjaan Umum (PU) belum memiliki sistem informasi yang bisa mengawasi dan mengevaluasi semua proyek secara bersamaan dan juga memberikan gambaran geografis lokasi proyek secara keseluruhan, setiap proyek yang dikerjakan juga memiliki tempat dan tingkat keberhasilan yang berbeda - beda, hal ini 
mengakibatkan informasi yang diterima belum maksimal. Sistem Informasi Geografis merupakan solusi dari permasalahan yang ada, dengan menggunakan sistem informasi geografis (SIG) data spasial (data geografi) dan data non spasial bisa dikelola bersamaan.

Dalam rangka pelaksanaan Peraturan Pemerintah Nomor 8 Tahun 2008 tentang Tahapan, Tata Cara Penyusunan, Pengendalian dan Evaluasi Pelaksanaan Perencanaan Pembangunan Daerah, dilihat perlu suatu "sistem informasi geografis monitoring dan evaluasi Proyek", dalam upaya meningkatkan kualitas operasional kinerja pembangunan pemerintah khususnya Dinas Pekerjaan Umum.

Dengan adanya "sistem informasi geografis monitoring dan evaluasi proyek dinas pekerjaan umum kota kotamobagu" ini, diharapkan bisa membantu pemerintah dalam memonitoring dan mengevaluasi proyek yang sedang berjalan maupun yang telah direalisasikan.

\section{LANDASAN TEORI}

A. Sistem Informasi Geografis (SIG)

Sistem Informasi Geografis (SIG) adalah sistem yang terdiri dari perangkat keras, perangkat lunak, data, manusia (brainware), organisasi dan lembaga yang digunakan untuk mengumpulkan, menyimpan, menganalisis, dan menyebarkan informasi informasi mengenai daerah - daerah di permukan bumi (Oktafia Dian : 2005).

Sistem Informasi Geografis/GIS (Geographic Information System) merupakan bentuk cara penyajian informasi terkait dengan objek berupa wilayah dalam bentuk informasi spatial (keruangan).

SIG mempunyai kemampuan untuk menghubungkan berbagai data pada suatu titik tertentu di bumi, menggabungkannya, menganalisa dan akhirnya memetahkan hasilnya. Data yang diolah pada SIG adalah data spasial yaitu sebuah data yang berorientasi geografis dan merupakan lokasi yang memiliki sistemkoordinat tertentu, sebagai dasar referensinya. Sehingga aplikasi SIG dapat menjawab beberapa pertanyaan seperti lokasi, kondisi, tren, pola dan pemodelan. Kemampuan inilah yang membedakan SIG dengan sistem informasi lainnya.

\section{B. Pemantauan (Monitoring) dan Evaluasi}

Pemantauan (monitoring) adalah prosedur penilaian yang secara deskriptif dimaksudkan untuk mengidentifikasi dan/atau mengukur pengaruh dari kegiatan yang sedang berjalan (on-going) tanpa mempertanyakan hubungan kausalitas. (Kumorotomo Wahyudi : 2007)
Sedangkan Evaluasi, PP No.39/2006 Evaluasi merupakan rangkaian kegiatan membandingkan realisasi masukan (input), keluaran (output) dan hasil (outcome) terhadap rencana dan standar.

\section{Pengertian Web Site}

Web adalah salah satu aplikasi yang berisikan dokumen-dokumen multi media(teks, gambar, suara, animasi, video) didalamnya yang menggunakan protokol HTTP (hypertext transfer protocol) dan untuk mengaksesnya menggunakan perangkat lunak yang disebut browser (Azmi Nurul : 2013).

\section{Pengertian Google Maps API}

Definisi menurut Wikipedia Google Maps adalah sebuah jasa peta globe virtual gratis dan online disediakan oleh Google dapat ditemukan di http://maps.google.com. Google Maps menyediakan gambar resolusi tinggi satelit untuk daerah perkotaan sebagian besar di Amerika Serikat (termasuk Hawaii, Alaska, PuertoRico, dan US Virgin Islands), Kanada, dan Inggris, serta sebagai bagian dari Australia dan banyak negara lainnya.

Seperti banyak aplikasi web lainnya Google, Google Maps menggunakan JavaScript secara ekstensif. Beberapa tujuan dari penggunaan Google Maps API adalah untuk melihat lokasi, mencari alamat, mendapatkan petunjuk mengemudi dan lain sebaginya. Hampir semua hal yang berhubungan dengan peta dapat memanfaatkan Google Maps

\section{E. Hypertext Transfer Protocol HTTP}

HTTP adalah protocol yang menetukan aturan yang perlu diikuti oleh web browser dalam meminta atau mengambil suatu dokumen dan oleh web server dalam menyediakan dokumen yang diminta oleh web browser. Protokol ini di desain untuk mentransfer berkas yang berisi hypertext seperti berkas yang berisi HTML yang digunakan di World Wide Web. Server dari WWW biasanya dikenal dengan nama HTTPD (Swastikayana Wayan I : 2011).

\section{F. HTML}

Hypertext Markup Language adalah salah satu format yang digunakan untuk menulis halaman web, HTML ini berjalan di web browser dan memiliki fungsi untuk melakukan pemrograman aplikasi di atas web. HTML merupakan pengembangan dari standar pemformatan dokumen teks, yaitu standar Generalized Merkup Language . HTML sebenarnya adalah dokumen ASCII atau teks biasa, yang dirancang untuk tidak tergantung 
pada suatu sistem operasi tertentu (Swastikayana Wayan I : 2011).

\section{G. PHP (Perl Hypertext Preprocessor)}

PHP (Perl Hypertext Preprocessor) adalah merupakaan bahasa berbentuk skrip yang di tempatkan dalam server dan di proses di server. Selain itu juga PHP merupakan salah satu dari sekian banyak bahasa pemrograman HTML (Hypertext Markup Language). Dibuat oleh Rasmus Lerdorf diawali dengan membuatnya sebagai personal project dan disempurnakan oleh group six of developers dan lahir kembali dengan nama PHP.

Secara khusus, PHP dirancang untuk membentuk web dinamis. Artinya, PHP dapat membentuk suatu tampilan berdasarkan permintaan. PHP memiliki kemampuan yang baik dalam hal perhitungan matematika, dalam hal informasi jaringan e-mail dan regular expretion. Selain itu PHP juga mampu sebagai interface dengan database secara baik, support dengan bermacam-macam database server seperti MySQL, ORACLE, Sysbase.

\section{H. JavaScripts}

JavaScripts adalah nama implementasi Netscape Communication Corporation untuk ECMAScript standar, suatu bahasa skrip yang didasarkan pada konsep pemrograman berbasis prototipe. Bahasa ini terkenal karena penggunaannya di situs web pada sisi klien dan juga digunakan untuk menyediakan akses skrip untuk objek yang dibenamkan (embedded) di aplikasi lain. Walaupun memiliki nama serupa, namun JavaScript hanya sedikit sekali berhubungan dengan bahasa pemrograman Java. Secara semantik, JavaScript memiliki lebih banyak kesamaan/kemiripan dengan bahasa pemrograman Self. JavaSript digunakan untuk mengakses sebuah objek program bersama aplikasi-aplikasi lainnya. dan utamanya digunakan pada form klien disamping JavaScript sebagai pengembangan untuk websitewebsite. JavaScript mempunyai karakteristik yang dinamis, kuat, menjadi dasar bahasa untuk prototipe dengan fungsi-fungsi kelas utama. JavaScript di desain seperti Java tetapi tetap mudah dalam penanganannya (Swastikayana Wayan I : 2011).

I. MySQL

MySQL adalah Relational Database Management System (RDBMS) yang diditribusikan secara gratis dibawah lisensi GPL (General Public License). MySQL sebenarnya merupakan turunan salah satu konsep utama dalam database sejak lama yaitu SQL (Structured Query Language). SQL adalah sebuah konsep pengoperasian database terutama untuk pemilihan/seleksi dan pemasukan data yng memungkinkan pengoperasian data dikerjakan dengan mudah dan secara otomatis. (Ashar Darul : 2014).

\section{METODOLOGI PENELITIAN}

1. Metodologi Pengembangan Sistem Perangkat Lunak

(Alan Dennis dkk, 2015) dalam buku Systems Analysis and Design With UML Version 2.0 Menyatakan bahwa aplikasi yang akan dibuat dapat menggunakan metode RAD Methodology jika kemampuan mengembangkan sistem telah sesuai dengan penilaian kriteria seperti, spesifikasi kebutuhan pengguna belum jelas, teknologi yang digunakan jarang dilihat, aplikasi yang akan dibuat tidak terlalu rumit, bisa mengembangkan sistem dengan kemampuan yang baik, waktu yang digunakan tidak lama, serta ada proses kunjungan atau turun lapangan ketika mengerjakan suatu sistem.

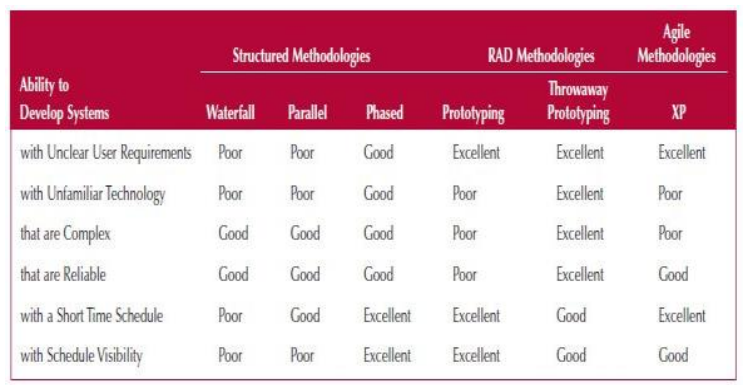

Gambar 1. Kriteria Untuk Pemilihan Metodologi

Analisa data dilakukan dengan 2 cara yang pertama dengan wawancara untuk menentukan metode penelitian dan Observasi tempat penelitian yang dapat dilihat pada bagian lampiran.

Rapid Application Development (RAD) merupakan salah satu metode pengembangan satu sistem informasi dengan waktu yang relatif singkat. Untuk pengembangan suatu sistem informasi yang normal membutuhkan waktu minimal 180 hari, akan tetapi dengan menggunakan metode RAD, suatu sistem dapat diselesaikan hanya dalam jangka waktu 30-90 hari (Noertjahyana Agustinus : 2002). RAD adalah sebuah strategi pengembangan sistem dimana menekan kecepatan pengembangan melalui keterlibatan user ekstensif dalam kecepatan, iterative (berulang) dan incrumental Constructiondari serangkaian fungsi dari prototype sebuah sistem yang pada akhirnmya akan mengalami perubahan secara bertahap menuju sistem akhir. 
Ide dasar dari RAD (Tim Pengembang Portal Resmi Unsrat : 2015) yaitu sebagai berikut:

1. Untuk lebih aktif lagi mempengaruhi user sistem dalam analisis, design, an aktifitas konstruksi

2. Untuk mengatur perkembangan sistem pada rangkaian yang terfokus, workshops yang intensif yang secara bersamaan mempengaruhi sistem owners, users, analysts, designers and bulders

3. Untuk mempercepat requirements analysis dan design phase (fase desain) melalui pendekatan konstruksi iterative.

4. Untuk mengurangi jumlah waktu yang sebelumnya lebih banyak digunakan oleh user untuk mengerti cara kerja sistem.

Dibawah ini adalah bagan metodologi pengembanga perangkat lunak RAD

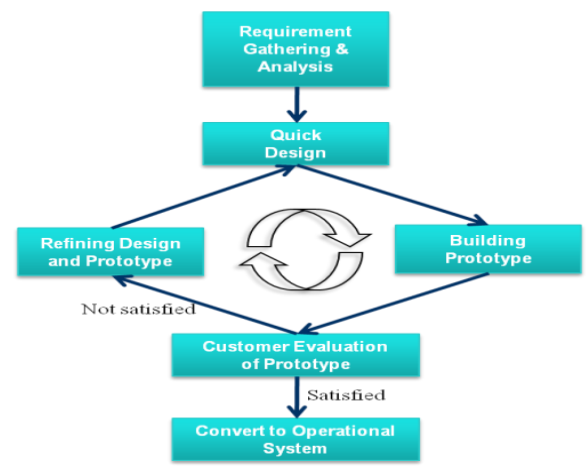

Gambar 2. Metode pengembangan Perangkat Lunak RAD

(Tim Pengembang Portal Resmi Unsrat : 2015)

Ada 4 tahapan yang harus dilakukan pada Metodologi RAD (Tim Pengembang Portal Resmi Unsrat : 2015) yaitu sebagai berikut:

\section{a. Analisis Persyaratan}

Tahap ini bertujuan untuk mengidentifikasikan kebutuhan pengguna, spesifikasi sistem melalui observasi dan pengumpulan data yang dilakukan terhadap stakeholders, sehingga aplikasi yang akan dibuat akan sesuai dengan yang dibutuhkan oleh pengguna. Pada bagian ini menggunakan tools UML.

\section{b. Analisis Modelling}

Bertujuan untuk menganalisis sistem yang sedang berjalan dari semua kegiatan yang terjadi pada sistem. Pada tahap ini, ada 2 tools UML yaitu usecase diagram dan activity diagram yang berfungsi untuk menggambarkan proses yang terjadi dalam sistem yang sedang berjalan. c. Desain Modelling

Bertujuan untuk melakukan perancangan sistem melalui analisis kebutuhan dan persyaratan dari pengguna yang telah dilakukan sebelumnya. Pada tahap ini tools UML yang digunakan yaitu usecase diagram, activity diagram, dan sequence diagram. Sehingga diharapkan sistem yang dibuat akan sesuai.

\section{d. Konstruksi}

Tahap ini akan menunjukkan platform, hardware, software, batasan implementasi, dan pengujian aplikasi yang telah dibangun apakah sudah sesuai dengan kebutuhan users dan spesifikasi persyaratan yang sebelumnya telah dianalisis. Bagian ini menggunakan tools UML.

\section{HASIL DAN PEMBAHASAN}

A. Tahap Analisis Persyaratan

Tahap ini mengidentifikasikan layanan, batasan, dan obyektivitas dari sistem pengumpulan data yang dilakukan. Selain itu, fase analisis persyaratan juga bertujuan untuk mendefinisikan persyaratan pengguna dan sistem.

1. Rencana Kerja

Rencana kerja dari riset ini dapat dilihat pada gambar dibawah ini:

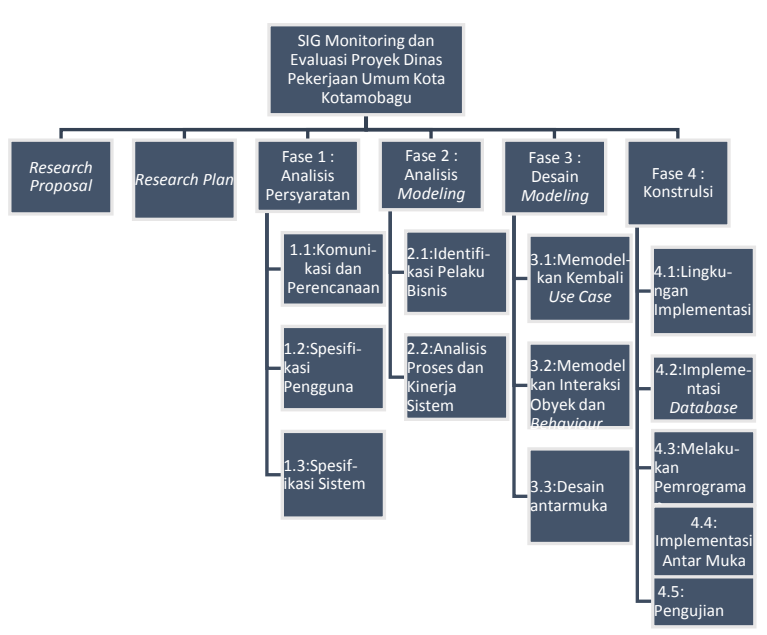

Gambar 3. Rencana Kerja Riset

2. Manajemen Resiko

Dalam setiap proyek, tentu saja diperhadapkan dengan berbagai macam resiko, berikut adalah resiko-resiko yang mungkin terjadi dalam pengembangan aplikasi. 
Tabel 1. Manajemen Resiko

\begin{tabular}{|l|l|l|l|l|}
\hline No. & Risk & Contigency & Cause & Effect \\
\hline 1. & $\begin{array}{l}\text { Perubahan } \\
\text { jadwal. }\end{array}$ & $\begin{array}{l}\text { Penyesuaia } \\
\text { n jadwal } \\
\text { kembali. }\end{array}$ & $\begin{array}{l}\text { Keterlamba } \\
\text { tan. }\end{array}$ & $\begin{array}{l}\text { Waktu lebih } \\
\text { lama. }\end{array}$ \\
\hline 2. & $\begin{array}{l}\text { Kesalahan } \\
\text { pemrogra } \\
\text { man. }\end{array}$ & $\begin{array}{l}\text { Perbaikan } \\
\text { kesalahan } \\
\text { pemrogram } \\
\text { an. }\end{array}$ & $\begin{array}{l}\text { Ketidak- } \\
\text { telitian. }\end{array}$ & $\begin{array}{l}\text { Keterlambata } \\
\text { n dan } \\
\text { performa } \\
\text { yang tidak } \\
\text { maksimal. }\end{array}$ \\
\hline 3. & $\begin{array}{l}\text { Perubahan } \\
\text { persyarata } \\
\text { nerangan } \\
\text { pengguna. }\end{array}$ & $\begin{array}{l}\text { Pemrogram } \\
\text { an kembali. }\end{array}$ & $\begin{array}{l}\text { Keinginan } \\
\text { user yang } \\
\text { berubah- } \\
\text { ubah. }\end{array}$ & $\begin{array}{l}\text { Keterlambata } \\
\text { n dan } \\
\text { performa } \\
\text { program } \\
\text { yang tidak } \\
\text { maksimal. }\end{array}$ \\
\hline 4. & $\begin{array}{l}\text { Kesalahan } \\
\text { analisis } \\
\text { sistem. }\end{array}$ & $\begin{array}{l}\text { Analisis } \\
\text { kembali } \\
\text { dan terjadi } \\
\text { perombakk } \\
\text { an desain. }\end{array}$ & $\begin{array}{l}\text { Keinginan } \\
\text { user yang } \\
\text { tidak } \\
\text { teridentifik } \\
\text { asi dengan } \\
\text { baik. }\end{array}$ & $\begin{array}{l}\text { Perbahan } \\
\text { fitur. }\end{array}$ \\
\hline
\end{tabular}

3. Manajemen Perubahan

Setiap proyek tentu saja mengalami perubahanperubahan dari perancangan awal. Berikut adalah daftar perubahan-perubahan yang terjadi selama pengembangan proyek.

\section{Tabel 2 Manajemen Perubahan}

\begin{tabular}{|c|c|c|c|c|}
\hline No. & $\begin{array}{c}\text { Perubahan } \\
\text { yang } \\
\text { dilakukan }\end{array}$ & $\begin{array}{c}\text { Perencanaan } \\
\text { awal }\end{array}$ & Penyebab & Akibat \\
\hline 1. & $\begin{array}{l}\text { Menyediak } \\
\text { an fitur } \\
\text { search by }\end{array}$ & $\begin{array}{l}\text { Tidak } \\
\text { menyediakan } \\
\text { fitur search by }\end{array}$ & $\begin{array}{l}\text { User dan } \\
\text { admin } \\
\text { memerluk } \\
\text { an fitur } \\
\text { pencarian }\end{array}$ & \begin{tabular}{l}
\multicolumn{2}{l}{ Penambaha } \\
$\mathrm{n} \quad$ fitur \\
dalam \\
sistem
\end{tabular} \\
\hline 2. & $\begin{array}{l}\text { Menyediak } \\
\text { an fitur } \\
\text { cetak } \\
\text { laporan } \\
\text { berdasarkan } \\
\text { tahun } \\
\text { anggaran }\end{array}$ & $\begin{array}{l}\text { Tidak } \\
\text { menyediakan } \\
\text { fitur cetak } \\
\text { laporan } \\
\text { berdasarkan } \\
\text { tahun }\end{array}$ & $\begin{array}{l}\text { Perlunya } \\
\text { cetak } \\
\text { laporan } \\
\text { berdasark } \\
\text { an tahun } \\
\text { anggaran } \\
\text { tertentu }\end{array}$ & $\begin{array}{l}\text { Penambaha } \\
\mathrm{n} \text { fitur cetak } \\
\text { laporan } \\
\text { dalam } \\
\text { sistem }\end{array}$ \\
\hline 3. & $\begin{array}{l}\text { penambaha } \\
\mathrm{n} \quad \text { fitur } \\
\text { progress } \\
\text { icon } \\
\text { berdasarkan } \\
\text { warna } \\
\text { tertentu }\end{array}$ & $\begin{array}{l}\text { Progress icon } \\
\text { yang } \\
\text { disediakan } \\
\text { belum } \\
\text { maksimal }\end{array}$ & $\begin{array}{l}\text { Agar } \\
\text { tingkat } \\
\text { penyelesai } \\
\text { an proyek } \\
\text { memiliki } \\
\text { progres }\end{array}$ & $\begin{array}{l}\text { Tampilan } \\
\text { marker } \\
\text { pada map } \\
\text { jadi } \\
\text { berfariasi } \\
\text { dengan } \\
\text { warna } \\
\text { marker } \\
\text { yang } \\
\text { berbeda }\end{array}$ \\
\hline
\end{tabular}

4. Spesifikasi Pengguna

Tahap ini akan mengidentifikasi dan menetapkan kebutuhan pengguna. Tahap ini terbagi atas identifikasi target pengguna, pengumpulan dan pemrosesan data, identifikasi dan analisis masalah dan kesempatan, dan identifikasi prioritas dari kebutuhan pengguna.

Daftar Pengguna Beserta Tugas dan Tanggung Jawabnya

Spesifikasi pengguna dari sistem informasi geografis ini, dapat dilihat pada tebel dibawah ini:

Tabel 3. Daftar Stakeholder Beserta Tanggung Jawabnya

\begin{tabular}{|l|l|}
\hline \multicolumn{1}{|c|}{ Stakeholders } & Tugas dan Tanggung Jawab \\
\hline Kepala Admin Dinas PU & $\begin{array}{l}\text { Melihat, mengelolah data } \\
\text { proyek, mencetak laporan, } \\
\text { mengelolah data admin } \\
\text { pengawas lapangan }\end{array}$ \\
\hline Admin Pengawas Lapangan & $\begin{array}{l}\text { Melihat, mengelolah data, } \\
\text { mencetak laporan }\end{array}$ \\
\hline User / masyarakat & Melihat dan mencetak laporan \\
\hline
\end{tabular}

B. Analisis Modelling

Tahap ini menganalisa semua kegiatan dalam arsitektur secara keseluruhan dengan melibatkan indentifikasi dan deskripsi abstraksi sistem perangkat lunak yang mendasar dan hubungan-hubungannya serta untuk meningkatkan pemahaman terhadap permasalahan terhadap permasalahan tanpa mempertimbangkan solusi teknis. Pada penelitian ini ouput yang dihasilkan dari fase analisis modeling ini adalah diagram model logis dari sistem yang sedang berjalan, diantaranya use case diagrams, activity diagrams, dan class diagram.

a) Mengidentifikasi Pelaku Bisnis

Daftar Aktor berserta tugas dan tanggung jawabnya

Daftar actor pada sistem lama berserta dengan tanggung jawabnya dapat dilihat pada table dibawah ini:

Tabel 4. Daftar Aktor Berseta Tugas dan Tanggung Jawabnya

\begin{tabular}{|l|l|}
\hline Aktor & Tugas dan Tanggung Jawab \\
\hline $\begin{array}{l}\text { Admin Dinas PU / Kepala } \\
\text { Admin }\end{array}$ & $\begin{array}{l}\text { mengelolah data proyek, data } \\
\text { admin, serta bertanggung jawab } \\
\text { atas admin pengawas lapangan }\end{array}$ \\
\hline $\begin{array}{l}\text { Admin Pengawas } \\
\text { Lapangan }\end{array}$ & mengelolah data proyek \\
\hline
\end{tabular}




\begin{tabular}{|l|l|}
\hline $\begin{array}{l}\text { Pegawai dinas PU dan } \\
\text { Masyarakat }\end{array}$ & $\begin{array}{l}\text { Melihat dan mengunduh data / } \\
\text { informasi }\end{array}$ \\
\hline
\end{tabular}

b) Use Case Diagram

Use case diagram untuk versi awal dapat dilihat pada Gambar berikut.

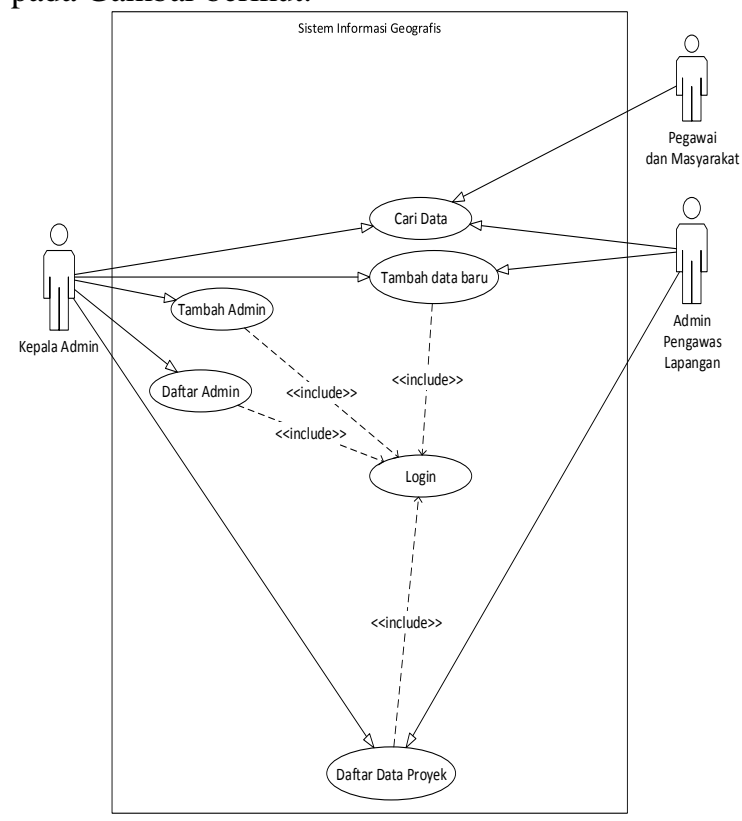

Gambar 4. Use Case Awl Aplikasi Monitoring

C. Desain Modeling

Tujuan dari tahap ini yaitu melakukan perancangan sistem berdasarkan analisis yang telah dilakukan sebelumnya. Tahap analisi dan dan desain mengalami perulangan hingga diperoleh rancangan sistem yang benar-benar memenuhi kebutuhan. Selain itu fase 3 RAD juga bertujuan untuk meberikan spesifikasi yang jelas dan lengkap kepada programmer dan teknisi. Hasil dari fase analisis modeling adalah basis data, antarmuka, dan spesifikasi desain.

Memodelkan kembali diagram use case untuk merefleksikan lingkungan implementasi.

\section{Use Case Diagram}

Use case diagram mengambarkan hubungan antara aktor dan sistem. Adapun aktor dalam Sistem Informasi Geografis Monitoring dan Evaluasi Proyek Dinas Pekerjaan Umum Kota Kotamobagu dibagi menjadi tiga yakni Super admin, Admin dan User.

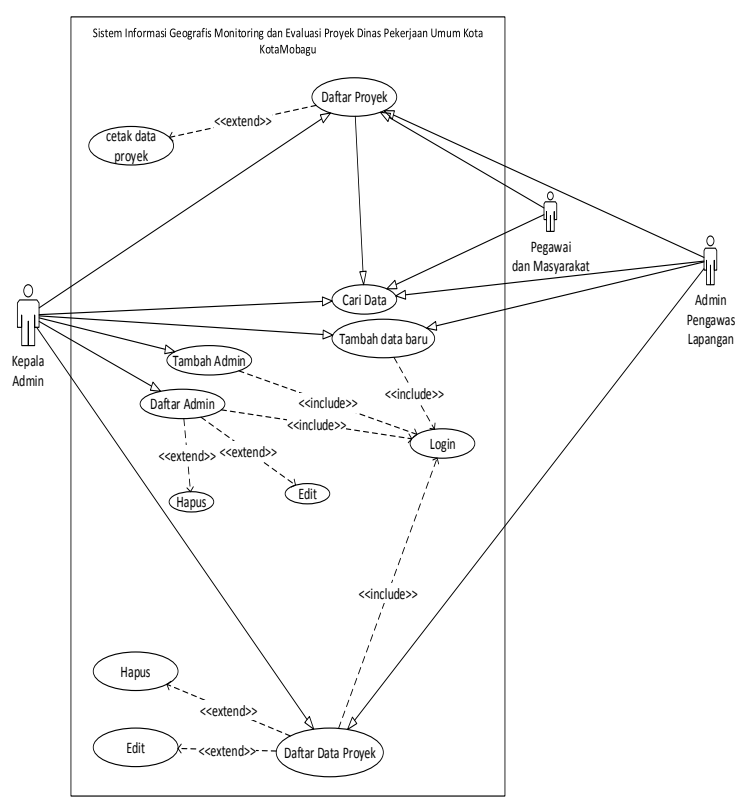

Gambar 5. Use Case Diagram SIG Monitoring dan Evaluasi Proyek Dinas Pekerjaan Umum Kotamobagu

Memodelkan Interaksi Obyek dan Behaviours

\section{Sequence diagram}

Tambah Data Baru

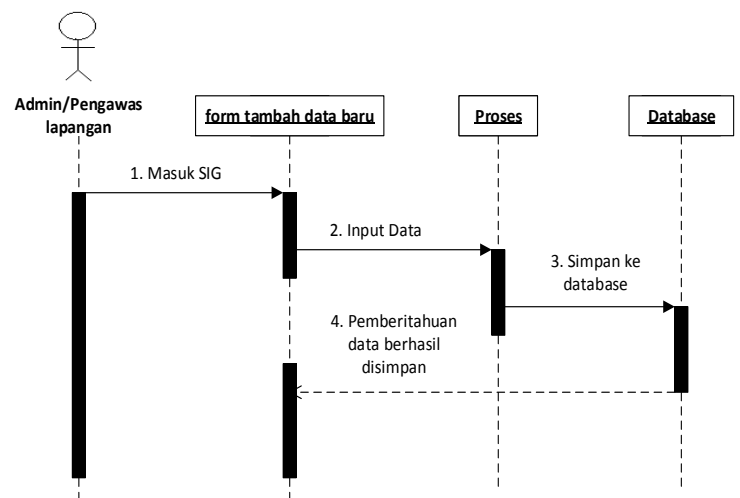

Gambar 6. Sequence Diagram Tambah Data Baru

\section{Tahap Konstruksi}

Fase Konstruksi bertujuan untuk menunjukkan platform, hardware dan softaware yang digunakan, serta batasan dalam implementasi, serta menguji perfomanasi prototype perangkat lunak yang telah dibangun agar dapat diketahui apakah prototype tersebut telah sesuai dengan spseifikasi analisis dan perancangan yang telah diidentifikasi sebelumnya.

a) Implementasi Antar Muka

Tampilan Halaman Awal Sistem Informasi Geografis 


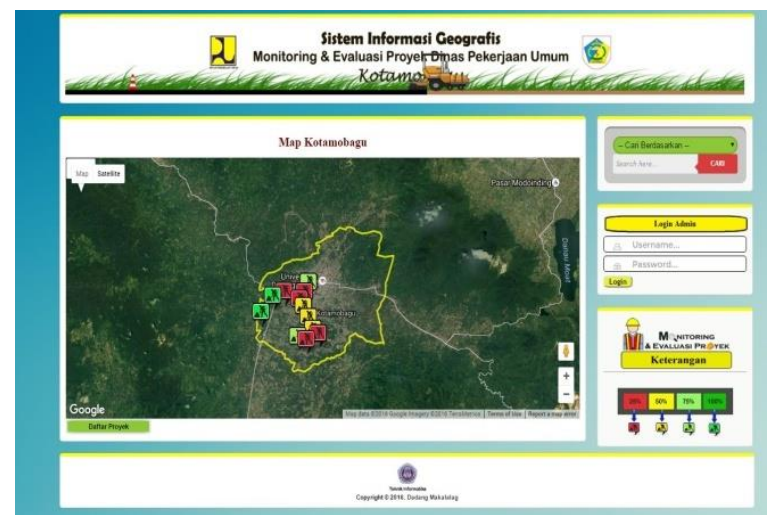

Gambar 7. Tampilan Awal Sistem Informasi Geografis Monitoring dan Evaluasi Proyek

Gambar diatas merupakan tampilan awal dari Sistem Informasi Gografis Monitoring dan Evaluasi Proyek, dimana terdapat beberapa menu yang dapat diakses oleh user seperti pemetaan proyek yang bias kita lihat pada tampilan awal, kemudian menu pencarian, menu daftar proyek, serta terdapat kolom keterangan mengenai progres proyek berdasarkan icon yang ada pada map.

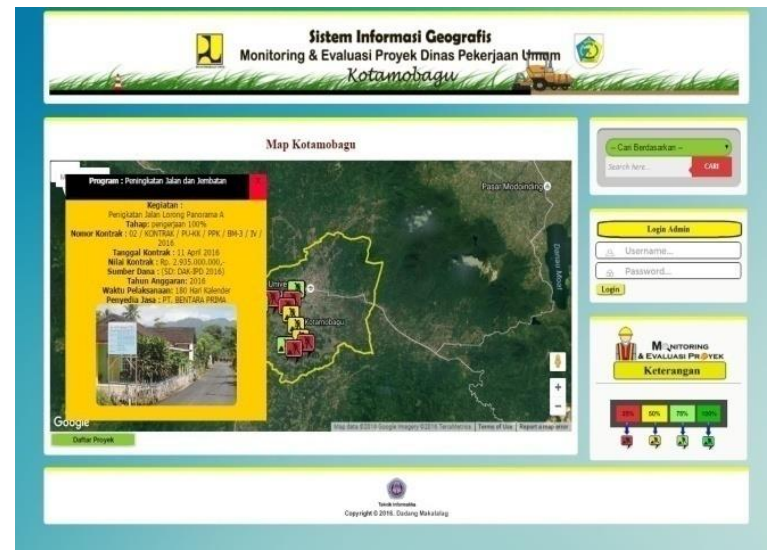

Gambar 8. Tampilan Informasi Yang Ditampilkan Oleh Info Window.

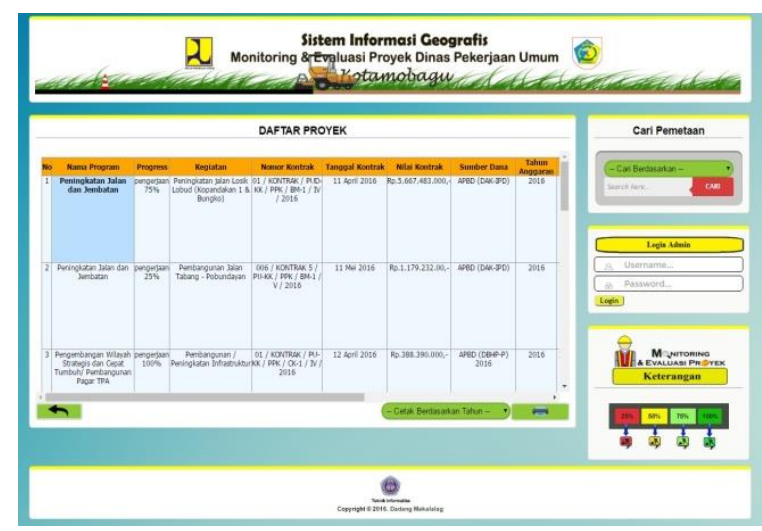

Gambar 9. Tampilan Ketika Masuk Kedalam Menu Daftar Proyek.

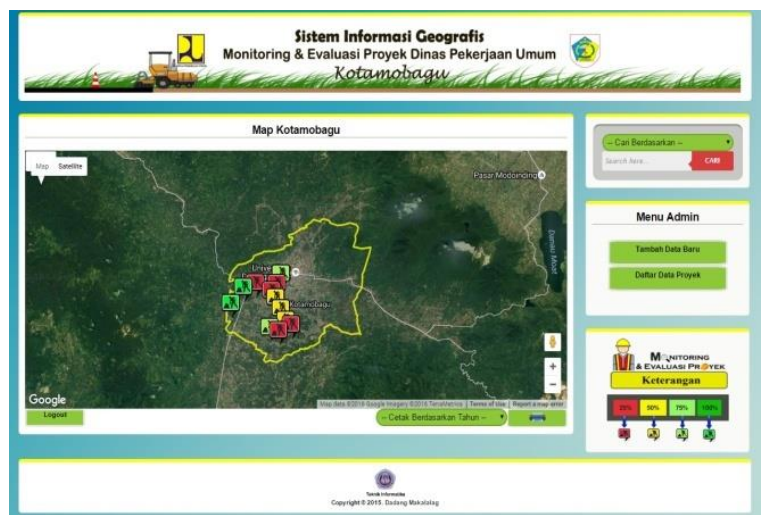

Gambar 10. Tampilan Halaman Awal Admin Pengawas Lapangan.

Pada gambar 10. diatas merupakan tampilan halman admin pengawas lapangan ketika admin berhasil memasukan username dan password dengan benar.pada halaman awal admin pengawas ini terdapat beberapa menu seperti tambah data baru, daftar data proyek yang berada disisi kanan menu sertacetak laporan proyek dan logout yang berada dibawah kolom pemetaan.

Tampilan Awal Halaman Kepala Admin

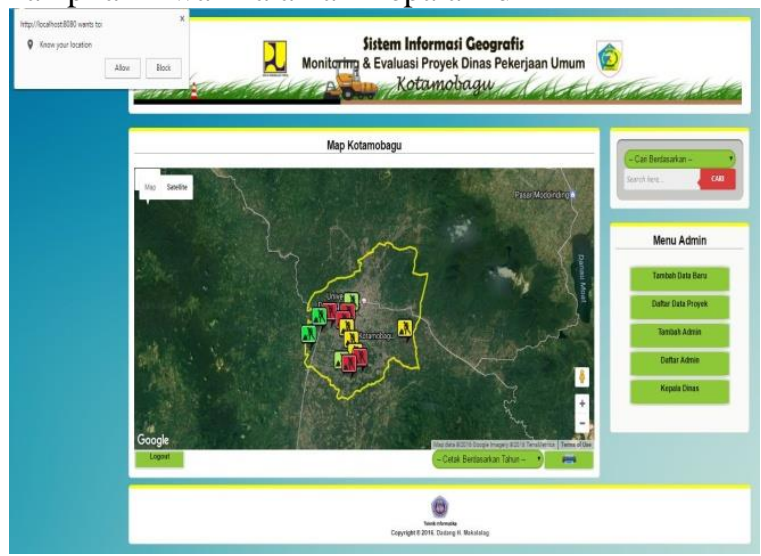

Gambar 11. Tampilan Awal Halaman Kepala Admin

Gambar 11. diatas sekilas sama seperti halaman Admin Pengawas Lapangan sebelumnya yang membedakannya hanyalah tambahan menu tambah admin, daftar admin dan kepala dinas yang berada disebelah kanan halaman kepala admin. Fungsi dari kepala admin sendiri sama dengan admin pengawas lapangan sebelumnya, yang membedakannya yaitu kepala admin dapat mengatur admin pengawas yang lain, bisa menambahkan admin yang baru, mengubah data admin serta menghapus admin tersebut, kepala admin lebih dikhususkan sebagai kepala pengawas dari admin yang lain.

Pada dasarnya tugas dan fungsi dari kepala admin sama dengan admin lain, jadi pembahasan 
berikutnya penulis hanya akan menjelaskan fitur-fitur yang belum dijelaskan dan hanya dimiliki oleh kepala admin seperti tambah admin, daftar admin dan kepala dinas.

\section{KESIMPULAN DAN SARAN}

\section{A. Kesimpulan}

Setelah melalui proses dan tahapan - tahapan yang dilakukan dalam penelitian ini, maka peneliti dapat menarik kesimpulan bahwa :

1. Dengan menggunakan metode pengembangan Sistem RAD (Rapid Application Development) Pembuatan Sistem Informasi Geografis Monitoring dan Evaluasi Proyek Dinas Pekerjaan Umum Kota Kotamobagu dapat dilakukan dalam waktu yang relatif singkat.

2. Sistem Informasi Geografis Monitoring dan Evaluasi Proyek Dinas Pekerjaan Umum Kota Kotamobagu dapat memberikan informasi yang berhubungan dengan Proyek secara cepat dan akurat kepada Instansi Pemerintahan serta masyarakat.

3. Dengan adanya Sistem Informasi Geografis ini dapat mempermudah Dinas Pekerjaan Umum Kota Kotamobagu memonitoring serta mengevaluasi proyek yang ada.

\section{B. Saran}

Setelah Melakukan penelitian dan juga membuat sistem informasi geografis monitoring dan evaluasi proyek, ada beberapa saran yang harus diperhatikan yaitu:

1. Agar dapat menampilkan peta Kotamobagu pada sistem informasi geografis diperlukan koneksi internet pada laptop, pc, serta smartphone yang membutuhkan koneksi internetyang stabil serta bagus.

2. Jika kedepannya ada yang ingin mengembangkan aplikasi Sistem Informasi Geografis ini maka dapat menambahkan fitur - fitur tebaru yang bisa berguna dan bermanfaat sesuai dengan kebutuhan.

\section{DAFTAR PUSTAKA}

Ashar Darul. 2004. Sistem Informasi Geografis Lokasi Pangkalan Ojek Kabupaten Kendal Berbasis Web, Fakultas Teknologi
Informasi, Universitas Stikubank (Unisbank) Semarang.

Azmi Nurul. 2013. Pemanfaatan Google Api (google Maps) Pada Website Pariwisata Menggunakan Framwork Codeignter, Jurusan Teknik Informatika, Sekolah Tinggi Manajemen Informatika Dan Komputer Amikom Yogyakarta.

Budiyati, IKA. 2005. Analisis Dan Perancangan Sistem Pengolahan Data Absensi Dan Lembur Karyawan Pada Kopegtel Dinasti Jakarta Timur Dengan Pendekatan Berorientasi Objek Menggunakan Uml. Fakultas Ilmu Komputer, Universitas Gunadarma.

Bodnar, Hopwood. 1993. Gambaran Umum Sistem Informasi dan Teknologi Informasi

Doktafia. 2009. Sistem Informasi Geografis.

Dennis Alan, dkk. 2015. Systems Analysis and Design With UML Version 2.0, University Of Virginia Amerika Serikat.

Gelinas, Oram, Wiggins. 1990. Gambaran Umum Sistem Informasi dan Teknologi Informasi.

Hidayat Herman. 2015. Sistem Informasi Geografis Pemetaan Nasabah Koperasi Studi Kasus Koperasi Keluarga Sejahtera Klaten, Program Studi Informatika, Fakultas Sains dan Teknologi, Universitas Islam Negeri Sunan Kalijaga Yogyakarta.

Indonesia, Presiden Repoblik. 2008. Tahapan, Tata cara Penyusunan, Pengendalian dan Evaluasi Pelaksanaan Rencana Pembangunan Daerah. Jakarta.

Jati Bangun. 2011. Sistem Informasi Geografis Berbasis Web Untuk Pemetaan Industri Kecil Di Kabupaten Bantul, Program Studi Teknik Informatika, Fakultas Sains dan Teknologi, UIN Sunan Kalijaga Yogyakarta.

Konsep Dasar SIG.

Kadir, Abdul 2003. Pengenalan Sistem Informasi, Andi, Yogyakarta

Kumorotomo Wahyudi. 2007. Konsep Dasar Pemantauan dan Evaluasi, Universitas Gadjah Mada. 
Mujahidin, Maulana. Pemantauan dan Evaluasi Pelaksanaan Proyek Pemeliharaan Bekala Salak dengan Project Monitoring and Control System (PMCS). J1 Margondu raya no 100. Depok.

Noertjahyana, Agustinus. 2002. Studi Analisis Rapid Aplication Development Sebagai Salah Satu Alternative Metode Pengembangan Perangkat lunak. Fakultas Teknologi Industri, Jurusan Teknik Informatika, Universitas Kristen Petra. Surabaya

Oktafia Dian. 2005. Sistem Informasi Geografis (SIG), Universitas Gunadarma.

Pramesti Putri Nectaria. 2013. Sistem Informasi Monitoring kemajuan pekerjaan Proyek Bangunan Sabo Dam Gunung Merapi, Universitas Atmajaya Yogyakarta.

Pamuji Dwi Teguh. 2013. Sistem Informasi Geografis (SIG) Pemetaan Hutan Menurut Klasifikasi Sebagai Potensi Hutan Lindung Di Kabupaten Blora. Fakultas Teknologi Informatika, Universitas Stikubank Semarang.

Rini Novita. 2010. Sistem Informasi Penjualan Barang, Program Diploma III Teknik Informatika, Fakultas Matematika dan Ilmu Pengetahuan Alam, Universitas Sebelas Maret Surakarta.

Swastikayana Wayan I. 2011. Sistem Informasi Geografis Berbasis Web Untuk Pemetaan Pariwisata Kabupaten Gianyar, Jurusan Teknik Informatika, Fakultas Teknologi Industri, Universitas Pembangunan Nasional Veteran Yogyakarta.

Sari S, Dewi Maya. 2007. Perancangan Sistem Informasi Geografis Berbasis Web Menggunakan Map Server. Fakultas Teknik Elektro Universitas Sumatra Utara. Medan.

Swastikayana E, I Wayan. 2011. Sistem informasi Geografis Berbasis Web Untuk Pemetaan Pariwisata Kabupaten Gianyer. Fakultas Teknologi Industri, Universitas Pembangunan Nasional Veteran Yogyakarta.

Tim Pengembang Portal Resmi Unsrat. 2015. Pembangunan Portal Resmi Universitas Samratulangi Manado.
Yuditya Ikhsyan Dhika. 2010. Aplikasi Peta Wisata Kuliner Kota Surakarta menggunakan Java 2 Micro Edition (J2ME), Program Diploma III Ilmu Komputer, Fakultas Matematika dan Ilmu Pengetahuan Alam, Universitas Sebelas Maret.

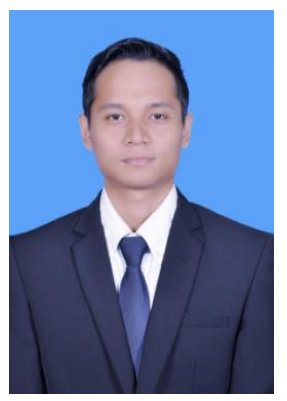

Sekilas dari penulis dengan nama lengkap Dadang Hermanto Makalalag, lahir di Maelang, Kabupaten Bolaang Mongondow, Provinsi Sulawesi Utara. Anak ke-2 dari 4 bersaudara dengan pendidikan Sekolah Dasar Negri 4 Kopandakan 1. Penulis lalu melanjutkan ke Sekolah Menengah Pertama Negeri 8 Kotamobagu. Lalu ke SMK TI Cokroaminoto Kotamobagu. Pada tahun 2011 melanjutkan ke Perguruan Tinggi di Universitas Sam Ratulangi dengan mengambil Jurusan Teknik Informatika. Pada Tahun 2015 bulan Juni, penulis membuat Skripsi demi memenuhi syarat Sarjana (S1) dengan penelitian berjudul Sistem Informasi Geografis Monitoring dan Evaluasi Proyek Dinas Pekerjaan Umum Kota Kotamobagu yang dibimbing oleh dua dosen pembimbing yaitu Yaulie Deo Y. Rindengan ST., MSc., MM dan Rizal Sengkey ST., MT sehingga pada tanggal 5 Desember 2016 penulis resmi lulus di Teknik Informatika Universitas Sam Ratulangi Manado menyandang gelar sarjana komputer dengan predikat sangat memuaskan. 